\title{
The impacts of cough: a cross-sectional study in a Finnish adult employee population
}

\author{
Heikki O. Koskela (10 ${ }^{1,2}$, Anne M. Lätti ${ }^{1,2}$ and Juha Pekkanen ${ }^{3,4}$
}

Affiliations: ${ }^{1}$ Unit for Medicine and Clinical Research, Pulmonary Division, Kuopio University Hospital, Kuopio, Finland. ${ }^{2}$ School of Medicine, Institute of Clinical Sciences, Faculty of Health Sciences, University of Eastern Finland, Kuopio, Finland. ${ }^{3}$ Dept of Public Health, University of Helsinki, Helsinki, Finland. ${ }^{4}$ Environmental Health Unit, National Institute for Health and Welfare, Kuopio, Finland.

Correspondence: Heikki O. Koskela, Unit for Medicine and Clinical Research, Pulmonary Division, Kuopio University Hospital, Kuopio, PL 100, 70029 KYS, Finland. E-mail: heikki.koskelaakuh.fi

ABSTRACT Given the very high prevalence of cough, little is known about its impacts.

A questionnaire was sent via e-mail to all public service employees in two towns in Finland. There were 373 subjects with acute cough, 174 with subacute cough and 421 with chronic cough. Cough-related quality of life was assessed with the Leicester Cough Questionnaire (LCQ) and depressive symptoms with Patient Health Questionnaire-2. In addition, data on doctor's visits and sick leave days were collected.

Mean LCQ (95\% CI) total scores were 16.2 (15.9-16.5), 14.5 (14.1-15.0) and 14.6 (14.3-14.9) among subjects with acute, subacute and chronic cough, respectively $(\mathrm{p}<0.001)$. The prevalence of depressive symptoms was $5.4 \%, 7.5 \%$ and $4.8 \%$, respectively, and $5.0 \%$ among subjects without current cough $(\mathrm{p}=0.50)$. The respective proportions of subjects with at least one doctor's visit due to cough during the previous year were $27.6 \%, 44.8 \%, 49.6 \%$ and $16.1 \%(\mathrm{p}<0.001)$. The respective proportions of subjects with at least one sick leave day due to cough during the previous year were $28.9 \%, 39.1 \%, 36.3 \%$ and $15.3 \%$ $(p<0.001)$. Any current cough was associated with an increased the risk of several (three or more) yearly doctor's visit due to any reason (adjusted odds ratio (aOR) 1.49, 95\% CI 1.27-1.76) and several (seven or more) yearly sick leave days due to any reason (aOR 1.43, 95\% CI 1.22-1.68).

Cough decreases quality of life, and has a large socioeconomic impact by increasing doctor's visits and sick leave days. However, it is not associated with depressive symptoms. The impacts of subacute and chronic cough are comparable, and larger than those of acute cough.

@ERSpublications

Cough has a deleterious effect on the quality of life. Within 1 year, it increases the probability of frequent doctor's visits by $49 \%$ and the probability of several sick leave days by $43 \%$, thus causing a significant socioeconomic burden. http://ow.ly/lXKn30mhKBK

Cite this article as: Koskela HO, Lätti AM, Pekkanen J. The impacts of cough: a cross-sectional study in a Finnish adult employee population. ERJ Open Res 2018; 4: 00113-2018 [https://doi.org/ 10.1183/23120541.00113-2018].

This article has supplementary material available from openres.ersjournals.com

Received: July 132018 | Accepted after revision: Oct 112018

Copyright $\odot$ ERS 2018. This article is open access and distributed under the terms of the Creative Commons Attribution Non-Commercial Licence 4.0. 


\section{Introduction}

Considering the fact that cough is the most common reason why people seek medical consultation, surprisingly little is known about its socioeconomic impacts. The impact of chronic (duration $>8$ weeks) cough has usually been investigated in patients attending specialist cough clinics [1-3]. However, the populations in these studies may be regarded as highly selected. Very few studies have investigated the impact of chronic cough in community-based populations. In a recent international community-based survey among subjects with chronic (>8 weeks) cough, $96 \%$ of the responders reported that cough affected their quality of life (QoL) [4]. 92\% reported feeling fed up or depressed due to their cough. Unfortunately, validated measures of QoL and depressive symptoms were not utilised. 93\% of the responders had visited a doctor regarding cough at least once. The number of sick leave days was not investigated. To the authors' knowledge, no studies have assessed the impacts of acute $(<3$ weeks) or subacute (3-8 weeks) cough. In the present study, the impacts of acute, subacute and chronic cough were assessed in a large community-based population.

\section{Methods}

Population

This was a cross-sectional study among all public service employees of two middle-sized towns in central Finland (Kuopio and Jyväskylä; 13980 employees altogether, mean age 46.6 years with $79.2 \%$ females). Invitation to the study and the questionnaire were sent via e-mail to the employees' e-mail addresses in March-April 2017. Answers were collected via an electronic reply form. One reminder message was sent if a subject had not responded within 2 weeks. The study was approved by the ethics committee of Kuopio University Hospital (289/2015). Permission to conduct the study was obtained from the town officials. The invitation mail to participate the study included detailed information about the study. The decision of the subject to reply was considered as informed consent.

\section{Questionnaire}

The questions were mainly adopted from two previous studies, the Health Behaviour and Health among the Finnish Adult Population study [5] and the Finnish National FINRISK study [6]. The first part of the questionnaire was filled in by all subjects. It included questions about the subject's household, pets, family incomes, occupation, physical activity, smoking history, alcohol consumption, general health-related questions, current medications, recent (within 1 month) somatic symptoms, as well as all disorders diagnosed by a doctor. Asthma-, rhinosinusitis- and reflux-related symptoms were sought by questions currently suggested for epidemiological studies [7-9]. Depressive symptoms were sought utilising the Patient Health Questionnaire-2 (PHQ-2) [10]. The subjects were asked about doctor's visits due to current cough, as well as doctor's visits during the last 12 months for cough and due to any reasons. The subjects were also asked about sick leave days due to cough and due to any reason within the last 12 months. The second part consisted of 23 detailed cough-related questions to be filled by subjects reporting current cough. It included questions about the cough bout frequency and cough duration, as well as the Leicester Cough Questionnaire (LCQ) to measure the cough-related QoL [2]. The questionnaire was first tested in a preliminary sample of 25 subjects and slightly revised before the final study. The questionnaire can be found as a supplementary file.

\section{Definitions}

Acute cough was defined as current (within 2 weeks) cough that had lasted for $<3$ weeks, subacute cough as current cough that had lasted for 3-8 weeks and chronic cough as current cough that had lasted for $>8$ weeks. Cough with any bout frequency was accepted. Current asthma was present if all the following conditions were fulfilled: presence of wheezing within 12 months, dyspnoea during wheezing and wheezing also without respiratory tract infections [7]. Chronic rhinosinusitis was present if there was either nasal blockage or nasal discharge (anterior or posterior nasal drip) and either facial pain/pressure or reduction/loss of smell for $>3$ months [8]. Gastro-oesophageal reflux disease was present if there was heartburn and/or regurgitation on $\geqslant 1$ day a week during the last 3 months [9]. Somatic symptom score was calculated by summing all reported somatic symptoms except cough, giving a value from 0 to 14 . Depressive symptoms were defined as PHQ-2 score $\geqslant 3$ [10]. Allergy was defined as a self-reported allergy to pollens, animals or food. Family history of chronic cough was defined as presence (now or in the past) of chronic (duration $>8$ weeks) cough in parents, sisters or brothers.

\section{Statistical analysis}

Descriptive data is presented as means and 95\% confidence intervals. The distribution of the doctor's visits and sick leave days differed significantly from the normal distribution (Kolmogorov-Smirnov test) and parametric tests could thus not be applied. ANOVA, Student's t-test, Mann-Whitney test and 
Chi-squared test were applied when appropriate. Bonferroni correction was applied in multiple comparisons. The following confounders were considered when analysing doctor's visits and sick leave days: age, sex, body mass index, years of education, family incomes, professional status, number of family members, pet ownership, moisture damage at home and in the workplace, smoking history, alcohol consumption, level of daily physical exercise, family history of chronic ( $>8$ weeks) cough, acetylsalicylic acid intolerance, allergies, somatic symptom score, depressive symptoms, current asthma, chronic rhinosinusitis, and gastro-oesophageal reflux disease. The variables showing at least suggestive $(\mathrm{p}<0.1)$ association with the outcome variables in the bivariate analyses were included in the multivariate analysis utilising binary logistic regression analysis with a backward directed stepwise process. A p-value $<0.05$ was accepted as the level of statistical significance but results showing a suggestive association $(\mathrm{p}<0.1)$ are also presented. All analyses were performed using SPSS version 22 for the personal computer (SPSS, Inc., Chicago, IL, USA).

\section{Results}

The response rate was $26.4 \%$ (3697 subjects; mean age 47.8 (95\% CI $47.5-48.2$ ) years, $82.6 \%$ females). The basic characteristics of the subjects are expressed in table 1 . There were 373 subjects with acute cough, 174 subjects with subacute cough and 421 subjects with chronic cough. Eight subjects could not estimate the cough duration. Of the 421 subjects with chronic cough, $57 \%$ had suffered from cough for $>1$ year and $26 \%$ for $>5$ years (figure 1 ).

Among the subjects with current cough, the LCQ total score and its domains were higher in subjects with acute cough than in subjects with the longer cough subtypes (table 2). The LCQ scores did not differ between subacute and chronic cough. The subjects with acute cough reported lower cough frequency than the subjects with the longer cough subtypes: the proportion of subjects with cough bouts daily or more often was 54\% among subjects with acute cough, 72\% among subjects with subacute cough and $64 \%$ among subjects with chronic cough $(\mathrm{p}<0.001)$.

The prevalence of depressive symptoms was 5.0\% among subjects without current cough, 5.4\% among subjects with acute cough, $7.5 \%$ among subjects with subacute cough and $4.8 \%$ among subjects with chronic cough ( $\mathrm{p}=0.50$ between the groups). The prevalence of depressive symptoms was $5.6 \%$ among the subjects with any current cough of any bout frequency ( $\mathrm{p}=0.45$ compared to the subjects without current cough) and $4.4 \%$ among the subjects with current cough occurring daily or more often $(\mathrm{p}=0.56)$.

Subjects with current cough made more doctor's visits than those without (table 3). Among the subjects with current cough, those with chronic cough visited doctors more often due to current cough than those with the other cough subtypes. When the doctor's visits were analysed within the period of last 12 months, there were no statistically significant differences between subacute and chronic cough but the subjects with acute cough visited doctors less often.

The subjects with cough had more sick leave days than those without (table 4). Among the subjects with current cough, those with acute cough had fewer sick leave days than the subjects with subacute or chronic cough. The number of sick leave days in subjects with subacute cough and chronic cough were comparable.

\section{TABLE 1 The basic characteristics of the subjects}

\begin{tabular}{|c|c|c|c|}
\hline Characteristic & No current cough & Current cough & p-value \\
\hline Subjects & 2720 & 976 & \\
\hline Age years & $47.6(47.2-48.0)$ & $48.7(48.0-49.4)$ & 0.006 \\
\hline Female sex & $82.2 \%$ & $83.9 \%$ & 0.24 \\
\hline Body mass index $\mathrm{kg} \cdot \mathrm{m}^{-2}$ & $26.4(26.2-26.6)$ & $27.2(26.9-27.5)$ & $<0.001$ \\
\hline Current smokers & $6.6 \%$ & $7.7 \%$ & 0.26 \\
\hline Ever-smokers & $31.4 \%$ & $31.5 \%$ & 0.96 \\
\hline Smoking history among ever-smokers pack-years & $6.16(5.57-6.75)$ & $6.98(5.92-8.05)$ & 0.17 \\
\hline Family income per year income class ${ }^{\#}$ & $3.05(3.02-3.08)$ & $2.97(2.92-3.03)$ & 0.021 \\
\hline Somatic symptom score & $2.36(2.29-2.43)$ & $3.50(3.36-3.65)$ & $<0.001$ \\
\hline
\end{tabular}


FIGURE 1 The duration distribution of current cough in 968 subjects. Eight subjects with current cough could not define the cough duration.

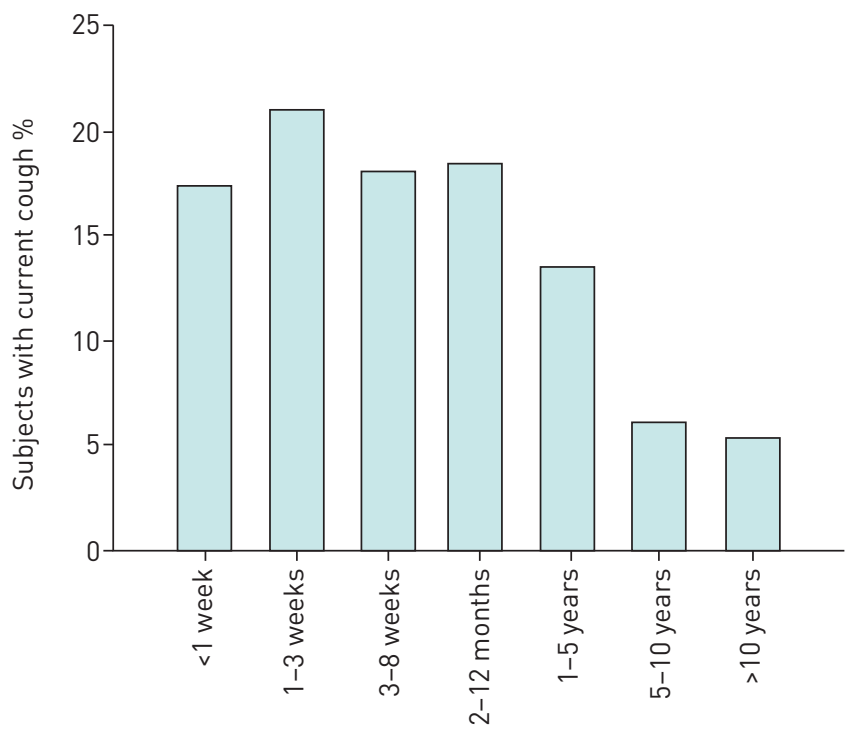

The following confounding factors were associated with both doctor's visits and sick leave days in bivariate analyses: age, sex, body mass index, somatic symptom score, depressive symptoms, family incomes and cigarette pack-years (data not shown). The multivariate analysis confirmed that current cough strongly increased the risk of doctor's visits and sick leave days (table 5). The multivariate analysis within cough subtypes revealed that chronic cough increased the risk of doctor's visits due to current cough more than subacute and acute cough (table 6). When the impacts were analysed within the period of last 12 months, the impact of acute cough was smaller than that of the two other cough subtypes whereas the impacts of subacute and chronic cough were comparable.

\section{Discussion}

The present community-based study among working-age, employed subjects revealed that in spite of the negative impacts of cough on QoL, it is not associated with depressive symptoms. Furthermore, cough substantially increases doctor's visits and sick leave days. The impacts of acute cough were smaller than the longer cough subtypes while the impacts of subacute and chronic cough were comparable.

In the present unselected cough population, the mean LCQ total score was 15.2 among subjects with cough of any duration and 14.6 among subjects with chronic cough. To our knowledge, there is only one previous community-based study utilising the LCQ reporting a mean total score of 17.3 among Danish subjects with chronic cough [11]. The rather low response rate may, at least partly, explain the worse QoL in the present population. Perhaps the subjects with severe cough were more willing to participate than subjects with mild cough. However, the LCQ total scores are usually still much lower in the populations from specialised cough clinics, with mean or median values of 12-13 [12-14]. These findings indicate that

TABLE 2 Leicester Cough Questionnaire total score and its three domains among subjects with current cough

\begin{tabular}{lcccc} 
& $\begin{array}{c}\text { Acute current } \\
\text { cough }(\mathbf{n = 3 7 3 )}\end{array}$ & $\begin{array}{c}\text { Subacute current } \\
\text { cough }(\mathbf{n = 1 7 4 )}\end{array}$ & $\begin{array}{c}\text { Chronic current } \\
\text { cough }(\mathbf{n = 4 2 1 )}\end{array}$ & $\begin{array}{c}\text { Any current cough } \\
\text { (n=976) }\end{array}$ \\
\hline $\begin{array}{l}\text { Total score } \\
\text { Physical }\end{array}$ & $16.2(15.9-16.5)^{* * *}$ & $14.5(14.1-15.0)$ & $14.6(14.3-14.9)$ & $15.2(15.0-15.4)$ \\
$\begin{array}{l}\text { Psychological } \\
\text { Social }\end{array}$ & $5.1(5.0-5.2)^{* * *}$ & $4.7(4.6-4.9)$ & $4.8(4.7-4.9)$ & $4.9(4.9-5.0)$ \\
& $5.5(5.4-5.6)^{* * *}$ & $4.8(4.7-5.0)$ & $4.7(4.6-4.8)$ & $5.0(4.9-5.1)$ \\
& $5.6(5.5-5.7)^{* * *}$ & $5.0(4.8-5.2)$ & $5.1(5.0-5.2)$ & $5.3(5.2-5.4)$ \\
\hline
\end{tabular}

Data are presented as mean $(95 \% \mathrm{Cl})$. Low score indicates poor cough-related quality of life. \# : eight subjects with current cough could not define the cough duration. ${ }^{* * *}: p<0.001$ between acute cough and the other cough subtypes, ANOVA; there were no statistically significant differences between subacute and chronic cough. 


\begin{tabular}{|c|c|c|c|c|c|}
\hline & $\begin{array}{l}\text { No current } \\
\text { cough }\end{array}$ & $\begin{array}{l}\text { Any current } \\
\text { cough }\end{array}$ & $\begin{array}{l}\text { Acute } \\
\text { current } \\
\text { cough }\end{array}$ & $\begin{array}{l}\text { Subacute } \\
\text { current cough }\end{array}$ & $\begin{array}{l}\text { Chronic } \\
\text { current } \\
\text { cough }\end{array}$ \\
\hline Subjects & 2720 & 976 & 373 & 174 & 421 \\
\hline $\begin{array}{l}\text { Subjects with any doctor's } \\
\text { visit due to current cough }\end{array}$ & NA & $26.6 \%$ & $9.9 \% * * *$ & $27.6 \% * * *$ & $41.6 \% * * *$ \\
\hline $\begin{array}{l}\text { Subjects with } \geqslant 3 \text { doctor's } \\
\text { visits due to current } \\
\text { cough }\end{array}$ & NA & $9.1 \%$ & $0.3 \% * * *$ & $3.5 \% * * *$ & $19.1 \% * * *$ \\
\hline $\begin{array}{l}\text { Subjects with any doctor's } \\
\text { visit due to cough within } \\
12 \text { months }\end{array}$ & $16.1 \%$ & $40.3 \%$ \#\#\# & $27.6 \%^{+++}$ & $44.8 \%$ & $49.6 \%$ \\
\hline $\begin{array}{l}\text { Subjects with } \geqslant 3 \text { doctor's } \\
\text { visits due to cough within } \\
12 \text { months }\end{array}$ & $2.6 \%$ & $13.8 \%$ \#\#\# & $6.2 \%^{+++}$ & $15.5 \%$ & $20.3 \%$ \\
\hline $\begin{array}{l}\text { Subjects with any doctor's } \\
\text { visit due to any reason } \\
\text { within } 12 \text { months }\end{array}$ & $81.7 \%$ & $88.9 \%$ \#\#\# & $85.7 \% *$ & $92.5 \%$ & $91.4 \%$ \\
\hline $\begin{array}{l}\text { Subjects with } \geqslant 3 \text { doctor's } \\
\text { visits due to any reason } \\
\text { within } 12 \text { months }\end{array}$ & $41.4 \%$ & $57.7 \%$ \#\#\# & $50.3 \% * *$ & $66.5 \%$ & $61.4 \%$ \\
\hline
\end{tabular}

subjects attending such clinics probably represent highly selected, very disabled cough subjects and that findings among such populations may not be applicable to the cough population in community.

The present study is, to our knowledge, the first to compare LCQ scores between acute, subacute and chronic cough. It revealed that acute cough has lesser impact on QoL than the longer cough subtypes whereas there were no differences between subacute and chronic cough. It has been shown before that coughrelated QoL is strongly related to objectively counted cough frequency during ambulatory recording [12]. In the present study, self-assessed cough bout frequency was lower in acute cough than in the longer cough subtypes, which may partly explain the differences in QoL. Furthermore, LCQ was originally developed for chronic cough. There is an "acute" version of it in which each item relates to the patient's

\begin{tabular}{|c|c|c|c|c|c|}
\hline & $\begin{array}{l}\text { No current } \\
\text { cough }\end{array}$ & $\begin{array}{l}\text { Any } \\
\text { current } \\
\text { cough }\end{array}$ & $\begin{array}{l}\text { Acute } \\
\text { current } \\
\text { cough }\end{array}$ & $\begin{array}{l}\text { Subacute } \\
\text { current cough }\end{array}$ & $\begin{array}{l}\text { Chronic } \\
\text { current } \\
\text { cough }\end{array}$ \\
\hline Subjects & 2720 & 976 & 373 & 174 & 421 \\
\hline $\begin{array}{l}\text { Subjects with any sick leave } \\
\text { day due to cough within } \\
12 \text { months }\end{array}$ & $15.3 \%$ & $34.0 \% * * *$ & $28.9 \% *$ & $39.1 \%$ & $36.3 \%$ \\
\hline $\begin{array}{l}\text { Subjects with } \geqslant 7 \text { sick leave } \\
\text { days due to cough within } \\
12 \text { months }\end{array}$ & $3.5 \%$ & $12.1 \%$ *** & $7.0 \% *$ & $13.8 \%$ & $16.0 \%$ \\
\hline $\begin{array}{l}\text { Subjects with any sick leave } \\
\text { day due to any reason } \\
\text { within } 12 \text { months }\end{array}$ & $76.1 \%$ & $85.8 \% * * *$ & $84.4 \%$ & $87.7 \%$ & $87.1 \%$ \\
\hline $\begin{array}{l}\text { Subjects with } \geqslant 7 \text { sick leave } \\
\text { days due to any reason } \\
\text { within } 12 \text { months }\end{array}$ & $32.4 \%$ & $45.7 \%$ *** & $40.1 \% * *$ & $54.4 \% * *$ & $48.0 \%$ \\
\hline
\end{tabular}

*: $p<0.05$ between acute cough and the other cough subtypes; ${ }^{* *}: p<0.01$ between acute and subacute cough; ${ }^{* * *}: p<0.001$ between any current cough and no current cough. 
TABLE 5 Multivariate analysis about the risk of consequences associated with current cough of any duration $(n=976)$

Consequence aOR $(95 \% \mathrm{CI})$

Any doctor's visit due to cough within 12 months

$3.12(2.62-3.71)$

$\geqslant 3$ doctor's visits due to cough within 12 months

$5.19(3.80-7.10)$

Any doctor's visit due to any reason within 12 months

$1.36(1.07-1.72)$

$\geqslant 3$ doctor's visits due to any reason within 12 months

$1.49(1.27-1.76)$

Any sick leave day due to cough within 12 months

$2.56(2.14-3.06)$

$\geqslant 7$ sick leave days due to cough within 12 months

$3.38(2.51-4.54)$

Any sick leave day due to any reason within 12 months

$1.60(1.30-1.98)$

$\geqslant 7$ sick leave days due to any reason within 12 months

$1.43(1.22-1.68)$

The subjects without current cough served as the control group ( $\mathrm{n}=2720$ ). The odds ratios (aOR) were adjusted for age, sex, body mass index, sum symptom score, depressive symptoms, family incomes and cigarette pack-years. Logistic regression analysis with backward directed stepwise process.

experience within a 24-h time frame, in contrast to the 2-weeks time frame in the traditional LCQ [15] However, it was impossible to use two different QoL instruments in the present type of study.

One previous community-based study [4] and two previous studies from specialised cough clinics $[16,17]$ suggested that chronic cough might be associated with depressive symptoms. On the contrary, in the present population, the prevalence of depressive symptoms was $5.0 \%$ among subjects without any cough and $4.8 \%$ among subjects with chronic cough. There are obvious reasons for this discrepancy. In the previous community-based study, a validated depressive symptom questionnaire was not used and the prevalence figures were not compared to those in healthy subjects [4]. The populations in the specialised cough clinics probably represent highly selected, very disabled cough subjects, as mentioned before. The population in the present study was unselected, a comparison with healthy subjects was performed and a well-validated

TABLE 6 Multivariate analysis about the risk of consequences associated with acute ( $\mathrm{n}=373$ ), subacute ( $n=174)$, and chronic current cough ( $n=421$ ) when compared to subjects without current cough $(n=2720)$

\begin{tabular}{|c|c|c|c|}
\hline Consequence & $\begin{array}{l}\text { Acute cough aOR } \\
(95 \% \mathrm{CI})\end{array}$ & $\begin{array}{l}\text { Subacute cough aOR } \\
\qquad(95 \% \mathrm{CI})\end{array}$ & $\begin{array}{l}\text { Chronic cough aOR } \\
{[95 \% \mathrm{Cl}]}\end{array}$ \\
\hline $\begin{array}{l}\text { Any doctor's visit due to current } \\
\text { cough }\end{array}$ & $1^{\#}$ & $3.62(2.24-5.83)$ & $6.53(4.42-9.66)$ \\
\hline $\begin{array}{l}\geqslant 3 \text { doctor's visits due to current } \\
\text { cough }\end{array}$ & $1^{\#}$ & $12.7(1.51-107)$ & $88.9(12.3-644)$ \\
\hline $\begin{array}{l}\text { Any doctor's visit due to cough } \\
\text { within } 12 \text { months }\end{array}$ & $1.84(1.42-2.38)$ & $3.79(2.72-5.28)$ & $4.59(3.64-5.78)$ \\
\hline $\begin{array}{l}\geqslant 3 \text { doctor's visits due to cough } \\
\text { within } 12 \text { months }\end{array}$ & 2.15 (1.30-3.55) & $6.01(3.64-9.90)$ & $7.45(5.22-10.6)$ \\
\hline $\begin{array}{l}\text { Any doctor's visit due to any reason } \\
\text { within } 12 \text { months }\end{array}$ & $1.14(0.82-1.58)$ & $2.22(1.21-4.06)$ & $1.60(1.10-2.32)$ \\
\hline $\begin{array}{l}\geqslant 3 \text { doctor's visits due to any reason } \\
\text { within } 12 \text { months }\end{array}$ & $1.21(0.95-1.53)$ & $2.22(1.57-3.16)$ & $1.49(1.18-1.89)$ \\
\hline $\begin{array}{l}\text { Any sick leave day due to cough } \\
\text { within } 12 \text { months }\end{array}$ & $2.04(1.58-2.64)$ & $3.19(2.27-4.48)$ & $2.69(2.11-3.42)$ \\
\hline $\begin{array}{l}\geqslant 7 \text { sick leave days due to cough } \\
\text { within } 12 \text { months }\end{array}$ & $1.97(1.24-3.12)$ & $3.87(2.35-6.36)$ & $4.53(3.15-6.52)$ \\
\hline $\begin{array}{l}\text { Any sick leave day due to any } \\
\text { reason within } 12 \text { months }\end{array}$ & $1.48(1.09-2.02)$ & $1.83(1.14-2.94)$ & $1.80(1.31-2.47)$ \\
\hline $\begin{array}{l}\geqslant 7 \text { sick leave days due to any } \\
\text { reason within } 12 \text { months }\end{array}$ & $1.23(0.97-1.56)$ & 2.05 (1.47-2.85) & $1.46(1.16-1.83)$ \\
\hline
\end{tabular}


depressive symptom questionnaire was utilised. In the present study, we could not diagnose clinical depression but measured the depressive symptoms. However, utilising the cut-off value $\geqslant 3$, PHQ-2 has a sensitivity of $83 \%$ and specificity of $92 \%$ for clinically confirmed major depression [10]. Of note, in a previous Finnish community-based study with $>6000$ mental health interviews the prevalence of major depression was $4.9 \%$, i.e. almost identical to the prevalence of depressive symptoms in the present population, supporting the reliability of PHQ-2 [18].

As expected, current cough was often associated with doctor's visits $[4,19,20]$. In previous community-based surveys, $91-93 \%$ of subjects with chronic cough had visited a doctor at least once $[4,20]$. In the present study, $41.6 \%$ of the subjects with chronic cough had visited a doctor at least once due to current cough. Though this is a high percentage, it is considerably lower than that in the previous studies. Very probably, the previous studies suffer from a significant reporting bias associated with the nonsystematic recruitment of the populations $[4,20]$.

Chronic cough was associated with larger number of doctor's visits due to current cough than both subacute and acute cough. However, when the doctor's visits were analysed within a period of 12 months, the difference between subacute and chronic cough vanished. There may be two explanations for this. First, in the majority of chronic cough subjects, the cough had lasted $>1$ year. In these subjects, the number of doctor's visits due to cough per one year can be smaller than that due to current cough. Second, there may be several episodes of subacute cough per 1 year. We have shown previously that subacute cough is associated with chronic rhinosinusitis and asthma [21]. These disorders are often episodic, activated by seasonal allergens or upper respiratory tract infections and these episodes can take place several times a year. Thus, within certain time limits, like 1 year, recurrent subacute cough may cause as many doctor's visits as chronic cough. Acute cough seems to prompt doctor's visits less often than the two longer cough subtypes.

Cough also increased the probability of doctor's visits due to any reason. In the model containing several confounders that could explain frequent doctor's visits, current cough independently increased the probability of such a visit by $36 \%$ within 1 year and the probability of frequent $(\geqslant 3)$ visits by $49 \%$. These figures can be regarded as highly significant with respect to health resource utilisation. Again, this impact was mainly associated with subacute and chronic cough.

Sick leave days due to cough are difficult to investigate. In Finland, a symptom is not a legitimate ground for a sick leave day. Therefore, diagnoses like "bronchitis" are used in health certificates. In the present study, the subjects were asked to subjectively estimate how many sick leave days took place due to cough. Unfortunately, the questionnaire did not include a question about sick leave days due to current cough. However, the sick leave days within the last 12 months were sought, both due to cough and due to any reasons. Strikingly, current cough independently increased the risk of a sick leave day due to any reason by $60 \%$, corroborating the large socioeconomic burden of cough. The model showing this included several confounders that could be associated with sick leave days, like age, sex, body mass index, sum symptom score, depressive symptoms and family incomes. The sum symptom score is an important confounder which probably represents somatisation. It describes the interindividual variation in how subjects recognise and report symptoms [22]. Again, subacute and chronic cough increased the sick leave days more than acute cough.

It seems that acute cough induces fewer doctor's visits and sick leave days than prolonged cough. One obvious reason for this is the lower cough frequency and less impaired QoL in acute cough. In addition, people probably are often aware of the self-limiting nature of acute cough or acute bronchitis and may regard a doctor's visit unnecessary. Furthermore, in many workplaces in Finland, an employee is entitled to $\leqslant 5$ days absenteeism even without a health certificate by a doctor. The latter facts may partly explain the relatively low number of doctor's visits in acute cough but not the relatively low number of sick leave days.

The three most commonly recognised chronic cough background disorders (chronic rhinosinusitis, asthma and gastro-oesophageal reflux disease) [23, 24] were included in the analyses as possible confounders. However, they were associated neither with the doctor's visits nor the sick leave days. These findings suggest that it is the cough itself, not the background disease, that mainly defines the impacts. This supports the rationale of cough hypersensitivity syndrome, a conception that long-standing hypersensitivity of cough reflex arch is an independent disorder [25, 26].

There are several shortcomings in the present study. All of the information used in the present analyses were based on self-reports in a cross-sectional design with the associated problems of biased reporting and lack of possibility to separate associations from causality. The participation rate was relatively low. It is possible that subjects with current cough were more interested to participate than those without. However, 
the responders and nonresponders did not differ with respect to age or sex distribution. The low participation rate probably affects more the cough prevalence values than the impact analyses. The generalisability of the study may be limited since the subjects were public service employees. Low social classes and old persons are therefore underrepresented. However, this population is very suitable to analyse doctor's visits and sick leave days because as public service employees, they are provided with a free health service and an equal, easy access to doctors. The impacts would probably have been greater if certain bout frequency criteria (e.g. daily cough) were utilised. However, we wanted an unselected cough population.

In conclusion, the present study shows that cough affects QoL and causes a substantial socioeconomic burden by increasing the probability of doctor's visits and sick leave days. However, it is not associated with depressive symptoms, not even chronic cough. The impacts of subacute and chronic cough are comparable, and larger than those of acute cough. Given the fact that the risk factors for subacute and chronic cough are very similar [21], it may be unnecessary to divide prolonged ( $>3$ weeks) cough to two subclasses. Focusing on the characteristics of a single cough episode may sometimes be misleading and more attention should be paid on the recurrence of cough episodes, even if they are short.

Acknowledgements: We thank Seppo Hartikainen (Istekki Ltd, Kuopio, Finland) for his assistance in creating the electronic questionnaire.

Conflict of interest: H.O. Koskela reports receiving grants from the Kuopion Alueen Hengityssäätiö Foundation and Hengityssairauksien Tutkimussäätiö during the conduct of the study, personal fees from Mundipharma Ltd, Orion Pharma Ltd, Oy, Eli Lilly Finland Ltd and Boehringer Ingelheim Finland Ltd as payments for giving scientific lectures in gatherings organised by medical companies, and personal fees from Takeda Leiras Ltd, Boehringer Ingelheim Ltd and Mundipharma Ltd to visit international scientific meetings, and owns shares of Orion Pharma Ltd worth €22000. A.M. Lätti reports receiving grants from the Kuopion Alueen Hengityssäätiö Foundation and Hengityssairauksien Tutkimussäätiö during the conduct of the study; and personal fees from Orion, Boehringer-Ingelheim and Roche to visit international scientific meetings outside the submitted work. J. Pekkanen has nothing to disclose.

Support statement: The study was funded by grants from the Kuopion Alueen Hengityssäätiö and Hengityssairauksien Tutkimussäätiö foundations. They had no input in the development of the research and manuscript. Funding information for this article has been deposited with the Crossref Funder Registry.

\section{References}

1 French CL, Irwin RS, Curley FJ, et al. Impact of chronic cough on quality of life. Arch Intern Med 1998; 158: $1657-1661$.

2 Birring SS, Prudon B, Carr AJ, et al. Development of a symptom specific health status measure for patients with chronic cough: Leicester Cough Questionnaire (LCQ). Thorax 2003; 58: 339-343.

3 Brignall K, Jayaraman B, Birring SS. Quality of life and psychosocial aspects of cough. Lung 2008; 186: Suppl. 1 55 .

4 Chamberlain SA, Garrod R, Douiri A, et al. The impact of chronic cough: a cross-sectional European survey. Lung 2015; 193: 401-408.

5 National Institute for Health and Welfare. Suomalaisen aikuisväestön terveyskäyttäytyminen ja terveys (AVTK) [Health Behaviour and Health among the Finnish Adult Population]. https://thl.fi/en/tutkimus-ja-kehittaminen/ tutkimukset-ja-hankkeet/aikuisten-terveys-hyvinvointi-ja-palvelututkimus-ath/aiemmat-tutkimukset/suomalaisenaikuisvaeston-terveyskayttaytyminen-ja-terveys-avtk Date last updated: April 15, 2014. Date last accessed: May 14, 2018.

6 National Institute for Health and Welfare. The National FINRISK Study. https://thl.fi/en/web/thlfi-en/researchand-expertwork/population-studies/the-national-finrisk-study Date last updated: October 2, 2017. Date last accessed: May 14, 2018.

7 Sa-Sousa A, Jacinto T, Azevedo LF, et al. Operational definitions of asthma in recent epidemiological studies are inconsistent. Clin Transl Allergy 2014; 4: 24.

8 Fokkens WJ, Lund VJ, Mullol J, et al. European position paper on rhinosinusitis and nasal polyps 2012. Rhinol Suppl 2012; 50: 1-298.

9 El-Serag HB, Sweet S, Winchester CC, et al. Update on the epidemiology of gastro-oesophageal reflux disease: a systematic review. Gut 2014; 63: 871-880.

10 Kroenke K, Spitzer RL, Williams JB. The Patient Health Questionnaire-2: validity of a two-item depression screener. Med Care 2003; 41: 1284-1292.

11 Colak Y, Nordestgaard BG, Laursen LC, et al. Risk factors for chronic cough among 14,669 individuals from the general population. Chest 2017; 152: 563-573.

12 Decalmer SC, Webster D, Kelsall AA, et al. Chronic cough: how do cough reflex sensitivity and subjective assessments correlate with objective cough counts during ambulatory monitoring? Thorax 2007; 62: 329-334.

13 Kelsall A, Decalmer S, Webster D, et al. How to quantify coughing: correlations with quality of life in chronic cough. Eur Respir J 2008; 32: 175-179.

14 Polley L, Yaman N, Heaney L, et al. Impact of cough across different chronic respiratory diseases: comparison of two cough-specific health-related quality of life questionnaires. Chest 2008; 134: 295-302.

15 Yousaf N, Lee KK, Jayaraman B, et al. The assessment of quality of life in acute cough with the Leicester Cough Questionnaire (LCQ-acute). Cough 2011; 7: 4.

16 Hulme K, Deary V, Dogan S, et al. Psychological profile of individuals presenting with chronic cough. ERJ Open Res 2017; 3: 00099-2016.

17 Dicpinigaitis PV, Tso R, Banauch G. Prevalence of depressive symptoms among patients with chronic cough. Chest 2006; 130: 1839-1843. 
18 Pirkola SP, Isometsä E, Suvisaari J, et al. DSM-IV mood-, anxiety- and alcohol use disorders and their comorbidity in the Finnish general population - results from the Health 2000 Study. Soc Psychiatry Psychiatr Epidemiol 2005; 40: 1-10.

19 Fujimura M. Frequency of persistent cough and trends in seeking medical care and treatment-results of an internet survey. Allergol Int 2012; 61: 573-581.

20 Everett CF, Kastelik JA, Thompson RH, et al. Chronic persistent cough in the community: a questionnaire survey. Cough 2007; 3: 5.

21 Lätti AM, Pekkanen J, Koskela HO. Defining the risk factors for acute, subacute and chronic cough: a cross-sectional study in a Finnish adult employee population. BMJ Open 2018; 8: e022950.

22 Croicu C, Chwastiak L, Katon W. Approach to the patient with multiple somatic symptoms. Med Clin North Am 2014; 98: 1079-1095.

23 Irwin RS, Baumann MH, Bolser DC, et al. Diagnosis and management of cough executive summary: ACCP evidence-based clinical practice guidelines. Chest 2006; 129: 23S.

24 Morice AH, McGarvey L, Pavord I. British Thoracic Society Cough Guideline Group. Recommendations for the management of cough in adults. Thorax 2006; 61: Suppl. 1, i24.

25 Chung KF. Chronic "cough hypersensitivity syndrome": a more precise label for chronic cough. Pulm Pharmacol Ther 2011; 24: 267-271.

26 Morice AH, Faruqi S, Wright CE, et al. Cough hypersensitivity syndrome: a distinct clinical entity. Lung 2011; 189: 73-79. 